\title{
Palabras del Rector de la Universidad de Chile, Doctor Ennio Vivaldi Vejar
}

Es un privilegio poder representar a la Universidad para agradecer a dos personas de extraordinaria trayectoria y a quienes la Universidad mucho debe a través de su carrera en el Instituto. También quiero agradecer al Instituto de Estudios Internacionales, por lo mucho y bien que ha hecho llevando adelante la vocación de representar el ideal de la Universidad de Chile. Me refiero al Director saliente y al Director entrante, que en sus discursos expresaron en forma manifiesta esa intención, esa combinación de lo que podríamos resumir como los valores de excelencia y compromiso. Por excelencia, entendemos un nivel académico que genere conocimiento, que forme nuevas generaciones y que sepa manejar, tratar y conocer los grandes problemas vigentes en un momento dado del desarrollo de la humanidad y del país. Por compromiso, la entrega de la Institución a una causa superior a los intereses de cada uno de los que participan en su labor, causa que si ustedes quieren representa a la Patria, al pueblo y, en algún sentido, a la humanidad, pero que nos sobrepasa y que tiene que ver con lo que es la vocación fundacional de esta Universidad.

Esa es la razón por la cual celebramos como creación de la Universidad a esta Institución, que nace dedicada a la formación de una nueva República, la República de Chile, cuya historia está indisolublemente ligada al área de las relaciones internacionales. Allí, la vocación pública se hace más evidente y en la cual la academia va desde lo más especifico, que es desde luego la defensa de nuestras fronteras como nación, hasta la forma en que posicionamos el pensamiento del país, la forma de ver el país, lo que son los grandes problemas de la humanidad o la comunidad internacional en un momento determinado, los temas de derechos humanos o la manera de 
relacionarse los países, los modelos económicos, el cambio e interacción de los modelos políticos y la representación de las corrientes en que se dan las relaciones entre los países.

Insisto en que este Instituto representa como pocos esta coexistencia de excelencia y compromiso. Quizá se puede tener excelencia sin compromiso, o al menos sin compromiso evidente o que esté presente en la conciencia de quien practica la excelencia, pero lo inverso no es posible, porque no se puede estar comprometido con una realidad si no se tiene de partida la tranquilidad espiritual y la conciencia de que va a hacerlo desde el mayor nivel de conocimiento alcanzable, es decir, desde la máxima excelencia que nos es dada en ese momento.

Por eso esta Universidad manifiesta su compromiso, en primer lugar, con el pueblo de Chile, asegurando que el nivel académico de cada una de sus unidades e instituciones es el más alto que hoy puede alcanzarse. Y creo que este Instituto lo ha hecho extraordinariamente bien y merece nuestro reconocimiento como Universidad, y como ha quedado de manifiesto en muchas oportunidades, de parte del país.

Si algo caracteriza al conocimiento es que, como ocurre para muchos filósofos, en última instancia es la única forma de validar una teoría o un concepto a partir de su capacidad predictiva. Porque en ciencia una ley es tal en la medida en que es capaz de predecir el acontecimiento de distintos fenómenos. Si se suma ese criterio, creo que hay que felicitar a este Instituto, que realmente ha tenido notable capacidad de anticiparse a los grandes problemas o situaciones internacionales que el país ha debido enfrentar.

Insisto en que este Instituto ha dado muestras de excelencia en la formación de profesionales y en la investigación científica, que hace junto con una tarea enorme de apoyo al Estado chileno. Pienso que el trabajo académico de este Instituto es particularmente notable y el país lo reclama hoy con particular intensidad.

Si tuviera que trazar una línea entre dónde se da una problemática atingente al tema de la educación, al tema de la Universidad, al tema de las políticas actualmente en Chile, diría que los supuestos debates entre, por ejemplo, universidades públicas y privadas no constituyen el quid del problema. Como Universidad de Chile, tenemos el mayor respeto por toda ins- 
titución de nuestro país, los problemas de cualquiera de ellas son problemas de la Universidad de Chile, porque esta se debe al país en su conjunto. No concebimos a la Universidad de Chile disputando, pidiendo un presupuesto y situaciones por el estilo con el resto del sistema universitario. Por el contrario, creo que en nuestra historia las páginas más hermosas son las de extraordinaria generosidad con que esta Universidad fue a crear escuelas, facultades en otras universidades del país para la Universidad de Chile porque precisamente su vocación es de respeto por otras instituciones que tienen puntos de vista propios. Me refiero en particular a la universidades católicas, ya que nadie podría negar el legado intelectual y cultural de la Iglesia Católica en los últimos dos mil años de Occidente.

Pienso en universidades notables como la Universidad de Concepción, o posteriormente la Universidad Austral, que hicieron esfuerzos absolutamente primigenios por llevar toda una idea de universidad a una región y permitieron una creación intelectual y académica al margen del centralismo, lo que si ustedes quieren es algo que se anticipó a un problema que vive actualmente el país en términos de respeto por las regiones, por la descentralización.

Esas tareas hacen que nosotros, como Universidad de Chile, tengamos el mayor respeto por ellas. Sin embargo y como muy bien se ha sido dicho acá, creo que este es el mejor lugar donde uno puede reafirmar con orgullo que existe también el concepto de una universidad estatal y esta es una que se debe al Estado de Chile, que piensa al Estado en su conjunto y no sólo una fracción de él, ni geográfica ni ideológica, al desarrollo económico, de las energías, de las tecnologías, de la salud de todos los chilenos. Lo que esta Universidad ha hecho en esas áreas por el país es enorme, piensa en el Estado chileno, en la educación chilena en su conjunto, se siente llamada por la situación de educación y de salud de cada niño de Chile, tarea que sentimos como propia y pedimos que se entienda que también es nuestra tarea.

Por eso, insisto en que el gran tema está presente aquí en parte fundamental y este Instituto puede hacer una contribución enorme. Si ustedes lo piensan, cualquier persona que tenga una mínima cultura de historia sabe, por ejemplo, que el concepto de Estado moderno surge con la Revolución 
Francesa, surge como concepto de Estado, surge con el capitalismo, y es fundamentalmente un arma que desarrolla el capitalismo. Eso impacta en todo país de Occidente que funciona en un esquema capitalista: tiene un Estado que cumple funciones específicas. No sé cómo, en este país, se entiende por Estado a una variante que es semicaricaturesca de un supuesto stalinismo y en la cual se habla del Estado como una entidad poco menos dictatorial. Cómo hemos podido llegar al nivel de negar las condiciones más básicas para entender la sociedad en nuestra vida pública común: eso me parece a mí notable e increíble.

Lo que nosotros apoyamos como Estado precisamente es la cohesión de los chilenos, es lo que une al país, lo que integra al país y en eso nos sentimos partícipes desde la educación pública y, muy en particular, en el rol que nos corresponde como Universidad. Creo que la más importante labor de la Universidad de Chile hoy día es que está llamada a retomar la idea de un país que discuta en política y que discuta sus alternativa de futuro en función de grandes ideas, de grandes ideales de sociedad, de definiciones de lo que somos los seres humanos, de qué sociedad queremos, qué es la felicidad en última instancia, qué es la justicia y qué es la equidad. En función de eso deberemos ser capaces de reconstruir grandes proyectos nacionales que permitan agrupar y a unir el país. Esa tarea pasa por la defensa de una labor intelectual como la que ustedes han ejemplarmente marcado acá, en una defensa irrestricta del país y la cosa pública.

Por último, creo que, además de esta vocación por la academia y por el país como Estado chileno, hay una tercera cosa que yo mencionaría particularmente en el caso de este Instituto y que es algo que uno ve en mayor o menor medida en toda la Universidad pero creo que en el caso de este Instituto ha sido particularmente notable. Se trata de cómo, desde su saber, de su disciplina desde su quehacer científico cada una de sus facultades contribuye en esa área que le corresponde a la Universidad en su conjunto. De hecho, por ejemplo, es posible verificar que muchas veces enfrentamos problemas jurídicos con la ayuda de nuestra facultad de Derecho. Uno querría que la facultad de medicina y su hospital fueran activos, en términos de lo que es la salud de los integrantes de la 
comunidad; hemos tenido al IDIEM y muchas otras instancias en las cuales recurrimos, a la Facultad de Arquitectura y otros miles de ejemplos en los que nos basamos cuando tenemos que resolver problemas de las facultades en sus quehaceres y deberes específicos.

Creo que hay pocos casos en los cuales esta visión se ha cumplido mejor y con mayor responsabilidad y voluntad como en el Instituto de Estudios Internacionales. Por ello, quiero también, como Universidad de Chile, agradecer a este Instituto lo mucho que ha hecho por las relaciones internacionales de la Universidad. Hay muchos nombres que representan esa actitud: Walter ha sido un aporte en muchas tareas de internalización de la Universidad; María Teresa Infante, hoy día a Pía Lombardo, tantos académicos que lo han hecho tan bien para guiar a esta Universidad.

Nosotros creemos que hoy es un momento en se plantea a Chile el tema del liderazgo en la región. Me parece tremendamente importante que, de nuevo, anticipatoriamente, este Instituto haya planteado el tema de la presencia regional. Pensamos que la Universidad de Chile está llamada a marcar un liderazgo en lo que es el concepto de universidad estatal y particularmente de lo que ello significa en esta región.

En esta tarea, estoy seguro de que el Instituto de Estudios Internacionales va a marcar una diferencia muy importante, va a ser capaz de guiar y de conducir un debate en el cual no solo iluminemos a nuestro pueblo, a nuestros gobernantes, sino que seamos también una fuente de cohesión, una fuente de integración para el conjunto de la relación de América Latina. Habremos cumplido entonces con lo que se espera en todo tipo de relación nacional e internacional: hermanar a la humanidad y construir objetivos comunes de lo que por ahora son intereses disgregados y encontrarnos a través del diálogo o la reflexión y el pluralismo, con una enorme y hermosa tarea común que nos haga parte de un mismo proyecto. 